\title{
Development of a Cavity-Backed Broadband Circularly Polarized Slot/Strip Loop Antenna With a Simple Feeding Structure
}

\author{
RongLin Li, Senior Member, IEEE, Bo Pan, Student Member, IEEE, Anya N. Traille, \\ John Papapolymerou, Senior Member, IEEE, Joy Laskar, Fellow, IEEE, and \\ Manos M. Tentzeris, Senior Member, IEEE
}

\begin{abstract}
A cavity-backed loop antenna is developed for producing broadband circularly polarized (CP) radiation. The antenna configuration consists of a slot loop and a strip loop. The slot loop radiates a CP wave at a lower frequency while the strip loop produces $\mathrm{CP}$ radiation at a higher frequency. A combination of the two frequencies leads to a bandwidth enhancement. The slot/strip loop antenna is fed by a single straight microstrip line. It is demonstrated that the cavity-backed slot/strip loop antenna can achieve an axial ratio $(\leq 3 \mathrm{~dB})$ bandwidth of $19 \%$ with good impedance matching. The antenna configuration is described and the operating principles for broadband circular polarization and impedance matching are analyzed. The antenna performance is confirmed by experimental results.
\end{abstract}

Index Terms-Broadband antenna, cavity-backed antenna, circularly polarized (CP) antenna, loop antenna, slot antenna.

\section{INTRODUCTION}

C AVITY-BACKED slot antennas have two major advantages over cavity-backed wire antennas, such as dipole, helix, and spiral antennas [1]. First, a slot antenna can be flush mounted on a metal surface; therefore, it is suitable for applications in mobile communications (such as IEEE 802.20 for mobile broadband wireless access) and radar systems of high-speed vehicles or aircraft [2]. Second, slot antennas can be easily fed by a microstrip line that is fabricated on the same substrate with the slot and is placed between the cavity and the substrate, thus avoiding the undesirable radiation from the feeding network. This is particularly important for applications in antenna arrays. Many types of slot configurations have been developed for producing circularly polarized (CP) radiation, such as annual slot [3], dual-spiral slot [4], rectangular slot [5], and cloverleaf slot [6]. However, these slot antennas have a narrow axial ratio (AR) bandwidth (usually $<5 \%$ for $\mathrm{AR} \leq 3 \mathrm{~dB}$ ). Archimedean spirals usually offer a much wider bandwidth in free space. Unfortunately, the presence of a ground plane (or a cavity) limits

Manuscript received February 23, 2006; revised August 28, 2007. This work was supported in part by the Georgia Electronic Design Center (GEDC), in part by an NSF CAREER Award ECS-9984761, in part by the NSF under Grant ECS-0313951, and in part by the NSF Packaging Research Center.

The authors are with the Georgia Electronic Design Center, School of Electrical and Computer Engineering, Georgia Institute of Technology, Atlanta, GA 30308 USA (e-mail: rlli@ece.gatech.edu).

Color versions of one or more of the figures in this paper are available online at http://ieeexplore.ieee.org.

Digital Object Identifier 10.1109/TAP.2007.915412 the bandwidth enhancement [7]. One way to remedy this limitation is to use absorbers inside the cavity or to terminate the spiral slot with tapered resistive loading [8], [9]. But it reduces the power efficiency. Recently, a bandwidth-enhanced $(\sim 15 \%$ for $\mathrm{AR} \leq 3 \mathrm{~dB}$ ) cavity-backed slot antenna has been presented in [10], but it requires a complicated feeding network. In this paper, we develop a broadband cavity-backed loop antenna with a simple feeding structure. The antenna configuration developed is considered to be a combination of a slot loop and a strip loop. The slot loop has a good CP performance at a lower frequency while the strip loop produces $\mathrm{CP}$ radiation at a higher frequency. A combination of the two frequencies leads to a bandwidth enhancement. The slot/strip loop is fed by a single straight microstrip line and a good impedance matching is achieved.

The antenna configuration is described in Section II. The operating principle for broadband circular polarization and impedance matching is analyzed in Section III. Finally experimental results are presented to verify the antenna performance.

\section{Description of the ANTEnNA}

The antenna configuration is shown in Fig. 1. The radiating element consists of a slot loop and a strip loop (so called a slot/strip loop) with a pair of parasitic slot loops inside the strip loop. The slot/strip loop with the parasitic loops is etched on a thin (thickness $=10$ mils), low-dielectric constant $\left(\varepsilon_{\mathrm{r}}=\right.$ 2.2) substrate (RT/duroid 5880) which is backed by a rectangular cavity. The cavity-backed slot/strip loop is fed by a microstrip feeding line that is fabricated on the same substrate with the slot/strip loop and is placed between the substrate and the cavity. The feeding line is divided into three sections: an open stub, a coupling stub, and a 50-ohms microstrip line. A coaxial line is connected to the 50 -ohms microstrip line for the purpose of measurement. The broadband circular polarization is achieved by adjusting the aspect ratio $\left(W_{s} / L_{s}\right)$ of the slot/strip loop and the depth $\left(D_{c}\right)$ of the cavity. By changing the length $\left(l_{\mathrm{op}}\right)$ of the open stub and the width $\left(w_{\mathrm{co}}\right)$ of the coupling stub, a good impedance matching can be obtained. The cavity-backed slot/strip loop antenna was designed for a C-band operation using Micro-Stripes 7.0 - a transmission-line matrix (TLM) based full-wave electromagnetic simulator [11]. The physical dimensions of the antenna are attached in the caption of Fig. 1. 


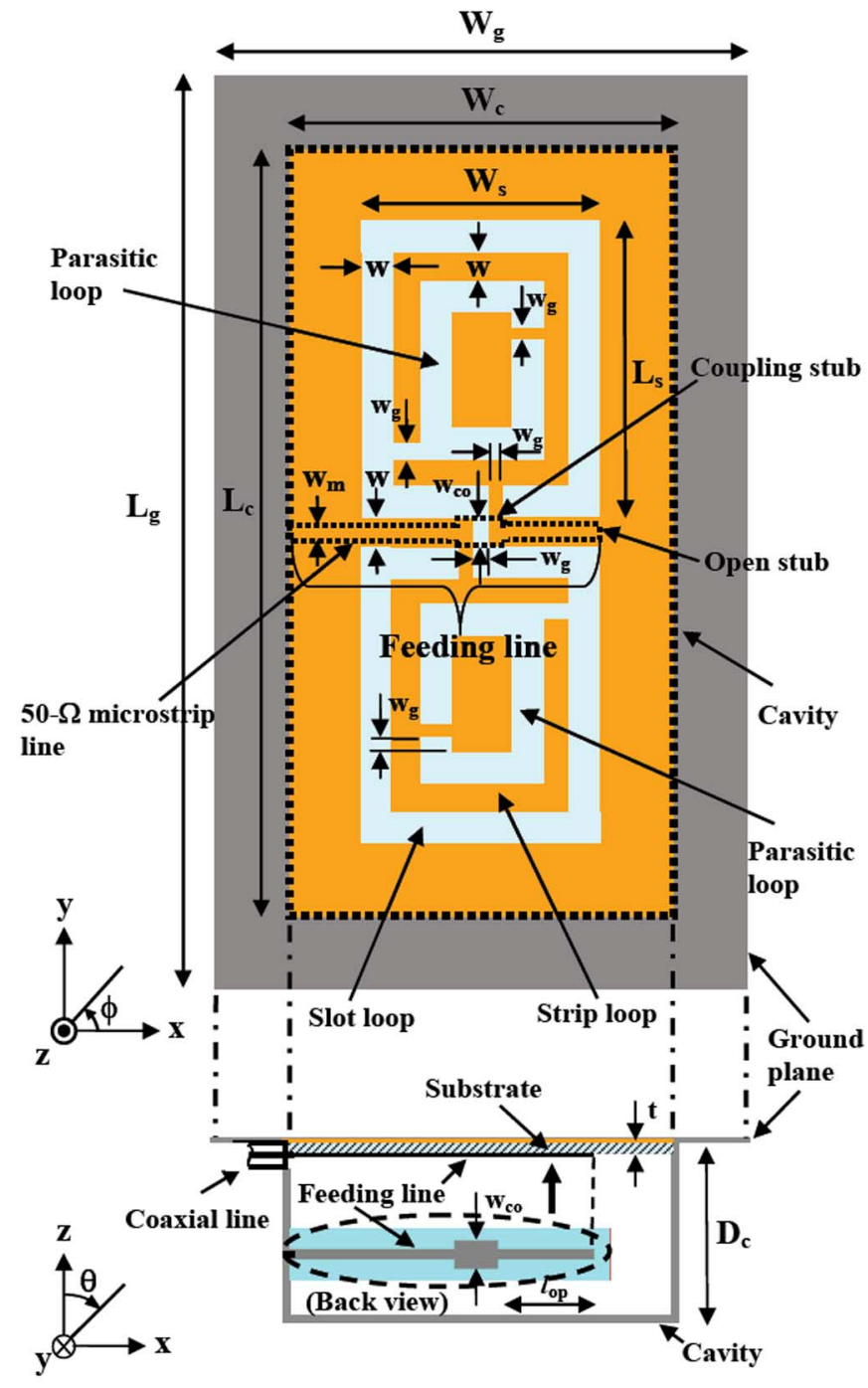

Fig. 1. Configuration of the cavity-backed broadband CP slot/strip loop antenna. $\left(W_{g}=36 \mathrm{~mm}, L_{g}=62 \mathrm{~mm}, W_{c}=26 \mathrm{~mm}, L_{c}=52 \mathrm{~mm}\right.$, $W_{s}=16 \mathrm{~mm}, L_{s}=20 \mathrm{~mm}, w=2 \mathrm{~mm}, w_{g}=1 \mathrm{~mm}, w_{\mathrm{m}}=0.78 \mathrm{~mm}$, $D_{c}=12 \mathrm{~mm}, \mathrm{t}=0.254 \mathrm{~mm}$; the width $\left(w_{\mathrm{co}}\right)$ of the coupling stub is $w_{\mathrm{co}}=w=2 \mathrm{~mm}$, the length of the coupling stub is $3 w_{\mathrm{g}}=3 \mathrm{~mm}$, the length of the open stub is $l_{\mathrm{op}}=6.5 \mathrm{~mm}$.).

\section{OPERATING PRINCIPLES}

\section{A. Broadband Circular Polarization}

As mentioned in previous sections, the slot/strip loop can be considered as a combination of a slot loop and a strip loop (see Fig. 2). For the slot loop [see Fig. 2(a)], a pair of shorting strips must be introduced in order to produce a $\mathrm{CP}$ wave [3], [5]. The winding sense of the slot loop decides the sense of its CP radiation, which is left-handed in spatial phase starting from the feeding point (the CP wave is propagating in the $z$ direction). When a voltage source is enforced at the feeding point, a traveling-wave magnetic current $\vec{M}$ can be excited on the slot loop [5]. If the slot loop has a perimeter of approximately one wavelength, the traveling-wave current can create electromagnetic waves in the far-field zone with $\sim 90$ degrees of spatial phase as well as time phase, thus achieving CP waves. Due to the nonuniform traveling-wave current distribution along the slot loop, the

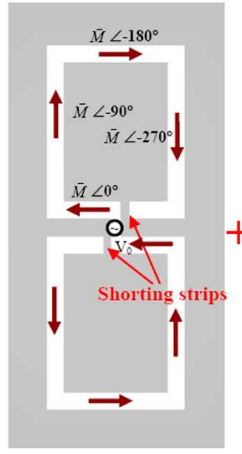

(a) Slot loop

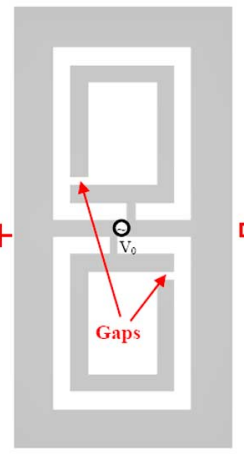

(b) Strip loop.

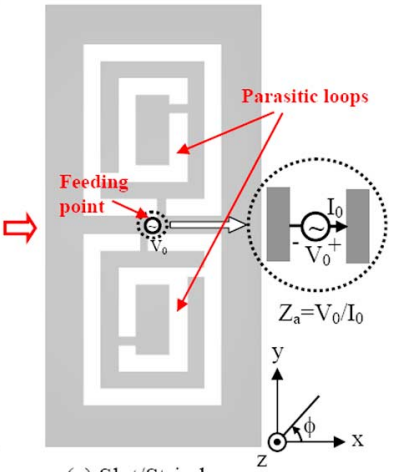

(c) Slot/Strip loop.
Fig. 2. Slot/strip loop considered as the combination of a slot loop and a strip loop.

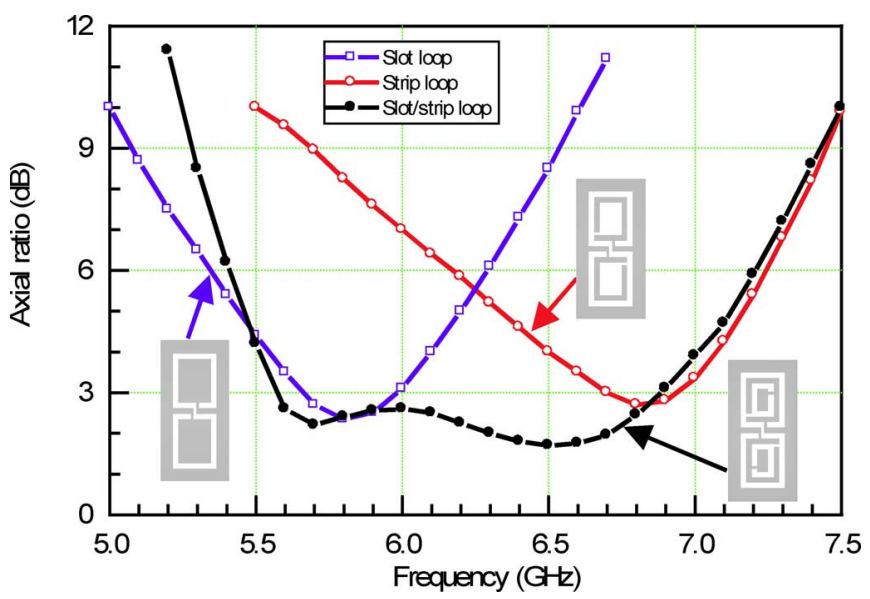

Fig. 3. Axial ratio for a slot loop, a strip loop, and a slot/strip loop.

CP waves created may be not perfect. And the slot loop usually has a narrow bandwidth for $\mathrm{CP}$ radiation since the electrical length of the slot loop is frequency dependent. Fig. 3 shows the AR in the $z$ direction simulated for the slot loop. It is seen that the slot loop has a minimum $\mathrm{AR}$ of $>2.5 \mathrm{~dB}$ at a lower frequency of $\sim 5.8 \mathrm{GHz}$. and a narrow bandwidth of $<5 \%$ for $\mathrm{AR} \leq 3$. In order to improve the AR bandwidth, we introduce a strip loop inside the slot loop [see Fig. 2(b)]. There is a pair of gaps into the strip loop [see Fig. 2(b)] for the generation of CP radiation [12], [13]. The strip loop moves the minimum AR to a higher frequency of $\sim 6.8 \mathrm{GHz}$ while maintaining a narrow bandwidth (see Fig. 3). The introduction of the strip loop improves the AR at the higher frequency, but worsens the AR at the lower frequency. For the AR bandwidth enhancement, we need to combine the slot loop and the strip loop into the same antenna aperture. To do so, we introduced a pair of small slots (also with a shorting strip on them) inside the strip loop [see Fig. 2(c)]. The introduced slots can be considered as a parasitic element of the slot loop, thus improving the bandwidth of the slot loop [14], [15]. Fig. 3 shows that the AR bandwidth of the slot/strip loop is increased to $\sim 20 \%$ for $\mathrm{AR} \leq 3 \mathrm{~dB}$. It should be noted that there would be no bandwidth enhancement without the strip loop (i.e., if the gaps on the strip loop were removed). Therefore, the slot/strip loop cannot be simply thought of as the complementary structure of a wire loop with parasitic elements 


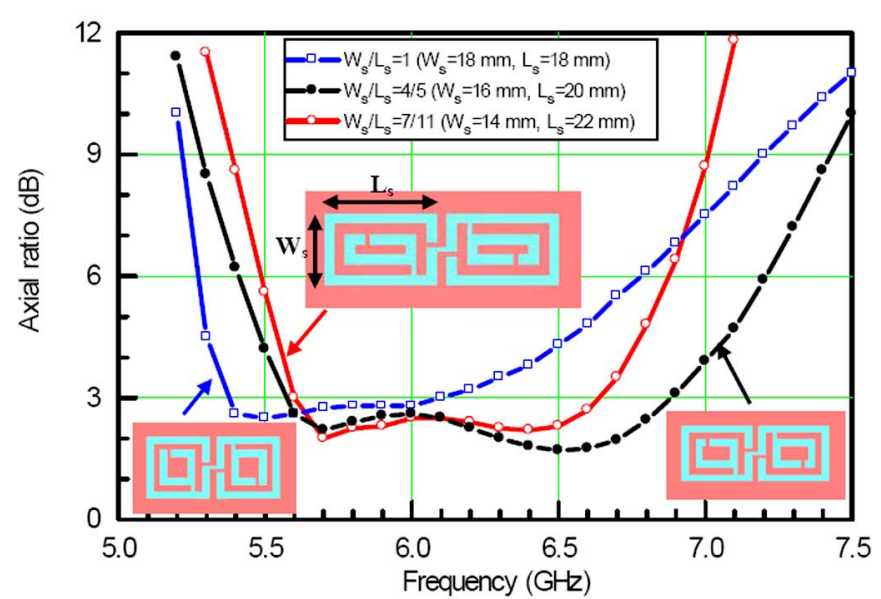

Fig. 4. Axial ratio at different aspect ratios $\left(W_{s} / L_{s}\right)$ of the slot/strip loop. $\left(W_{c}=28 \mathrm{~mm}\right.$ and $L_{c}=48 \mathrm{~mm}$ for $W_{s} / L_{s}=1, W_{c}=26 \mathrm{~mm}$ and $L_{c}=52 \mathrm{~mm}$ for $W_{s} / L_{s}=4 / 5, W_{c}=24 \mathrm{~mm}$ and $L_{c}=56 \mathrm{~mm}$ for $W_{s} / L_{s}=7 / 11$.).

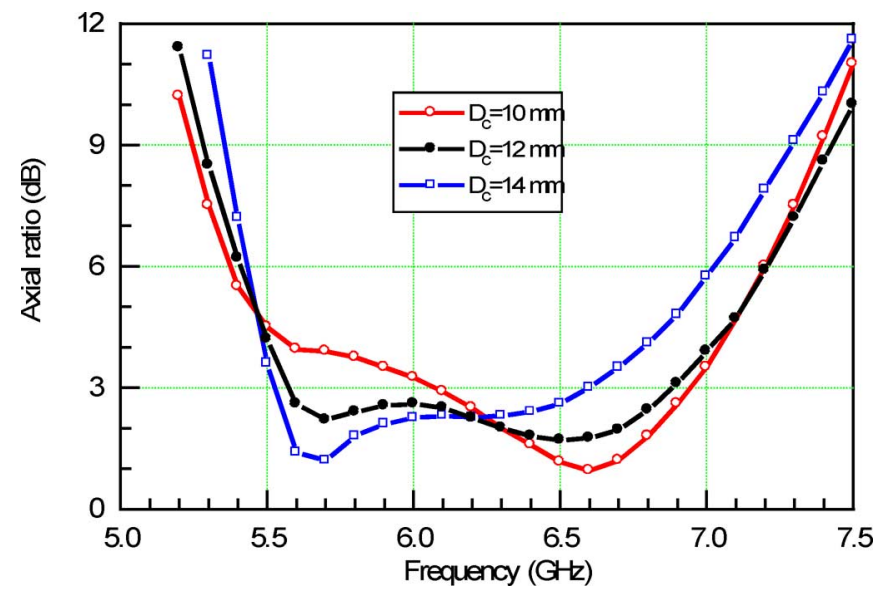

Fig. 5. Axial ratio at different depths $\left(D_{c}\right)$ of the cavity.

[15]. The AR bandwidth improvement can be considered as a result of the combination of a strip loop and a slot loop with a pair of parasitic slot loops.

The cavity-backed slot/strip loop antenna was optimized by changing the aspect ratio of the loop and the depth of the cavity. Fig. 4 shows the variation of $\mathrm{AR}$ as the aspect ratio $\left(W_{s} / L_{s}\right)$ is reduced from 1 (i.e., a square) to $7 / 11$. In the optimization, only the width and length of the cavity were adjusted with the aspect ratio to keep the distance (i.e., $5 \mathrm{~mm}$ ) from the sidewall of the cavity to the edge of the loop unchanged. It is found that the optimized aspect ratio is about $4 / 5$. A larger aspect ratio (e.g., 1) or a smaller aspect ratio (e.g., 7/11) would lead to a narrower AR bandwidth. The variation of AR with the depth $\left(D_{c}\right)$ of the cavity is displayed in Fig. 5. At a higher depth (e.g., $D_{c}=14 \mathrm{~mm}$ ), there is a good AR at a lower frequency but a bad AR at a higher frequency. As the depth decreases, the AR is improved at the higher frequency. But if the depth is further reduced (e.g., $D_{c}=10 \mathrm{~mm}$ ), the AR at the lower frequency becomes worse. Therefore there should be an optimal value for the depth, which is found to $D_{c}=12 \mathrm{~mm}$ for the proposed slot/strip loop antenna. The effect of the width $\left(W_{g}\right)$ of the ground plane on the AR performance is exhibited in Fig. 6. There is some effect due to the diffraction from the edge of the ground plane.

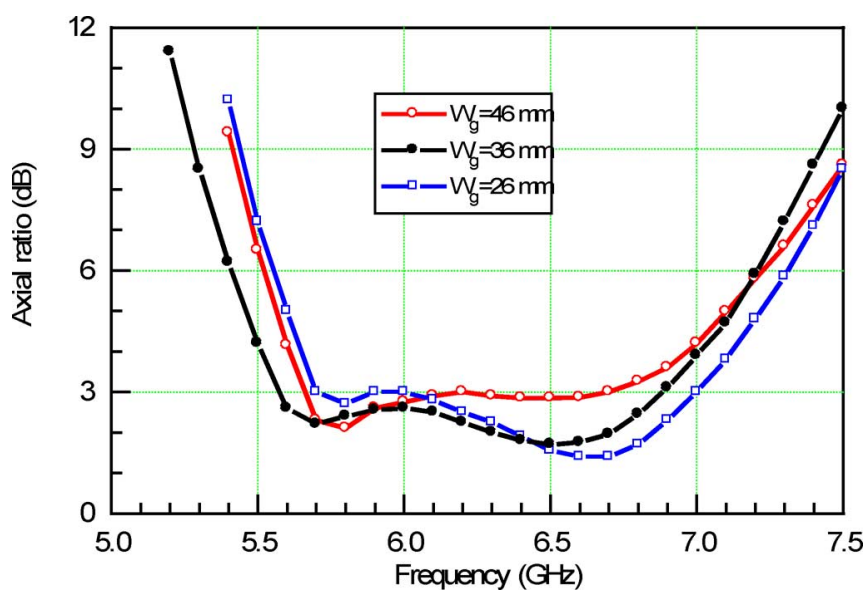

Fig. 6. The effect of the width ( $\left.W_{g}\right)$ of ground plane on the axial ratio of the slot/strip loop antenna.

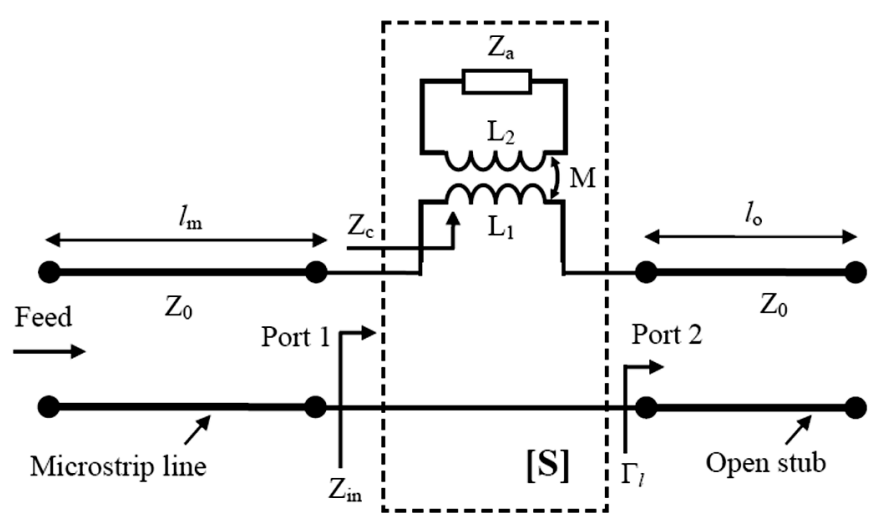

Fig. 7. Equivalent circuit for input impedance of the cavity-backed slot/strip loop antenna $\left(Z_{0}=50 \mathrm{ohms}, l_{\mathrm{m}}=W_{c} / 2=13 \mathrm{~mm}, l_{o}=l_{\mathrm{op}}+1.5 \mathrm{~mm}=\right.$ $8 \mathrm{~mm})$.

But it is not significant. For a certain ground plane, the slot/strip loop may be adjusted slightly for an optimal performance.

\section{B. Impedance Matching}

To understand the impedance matching of the slot/strip loop antenna, an equivalent circuit for the input impedance is presented in Fig. 7, where the slot discontinuity at the feeding point appears as a simple series impedance $Z_{c}$ to the microstrip line [16]. The impedance $Z_{\mathrm{a}}$ is the input impedance of the slot/strip loop when it is directly fed by a voltage source [see Fig. 2(c)]. The impedance $Z_{\mathrm{a}}$ directly simulated by enforcing a voltage gap feed is shown in Fig. 8. A loop around the center frequency (6.5 $\mathrm{GHz}$ ) is observed at the impedance locus, which means that the broadband property of the input impedance of the slot/strip loop is inherent, but not due to the feeding structure. The impedance $Z_{\mathrm{a}}$ is coupled to the microstrip line through the self-inductances ( $L_{1}$ and $L_{2}$ ) of the slot/strip loop and the coupling stub, and the mutual inductance $(\mathrm{M})$ between the two elements [17], leading to the series impedance $Z_{c}$. Since it is difficult to determine the values of $L_{1}, L_{2}$, and $\mathrm{M}$, we cannot directly calculate the series impedance $Z_{c}$. Instead, we can obtain $Z_{c}$ by considering the microstrip line-fed slot/strip loop as a two-port device with Port 1 defined at the 50-ohms microstrip line and Port 2 at the open 


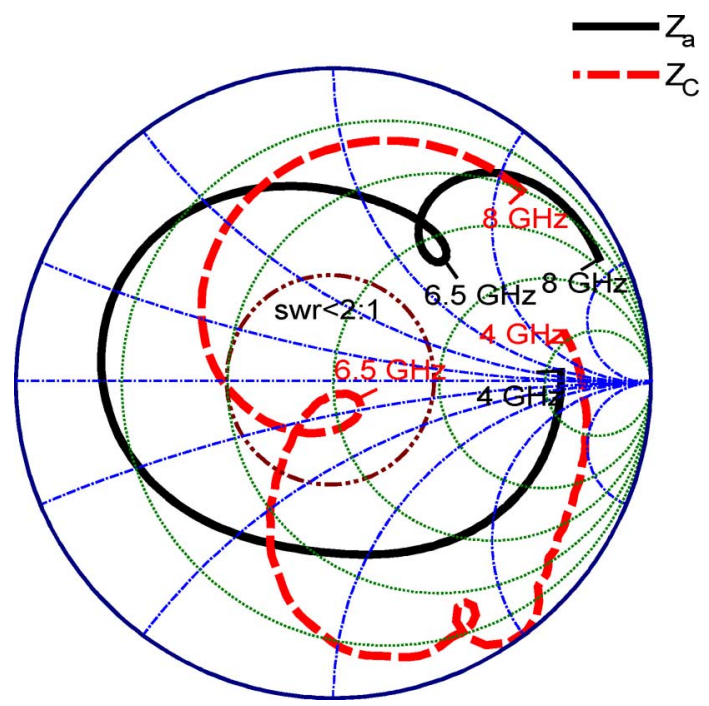

Fig. 8. Input impedance $Z_{\mathrm{a}}$ of the cavity-backed slot/strip loop antenna fed by a voltage source and the series impedance $Z_{c}$ calculated using the $\mathrm{S}$ parameters.

stub. From the S parameters of the two-port network, we have [18]

$$
Z_{c}=Z_{0} \frac{\left(1+S_{11}\right)\left(1+S_{22}\right)-S_{12} S_{21}}{2 S_{21}}
$$

where $Z_{0}(=50 \mathrm{ohms})$ is the characteristic impedance of the microstrip line. Note that the reference plane of the S parameters is defined at the center of the antenna (i.e., the feeding point shown in Fig. 2). The $S$ parameters of the two-port network can be obtained by numerical simulation. The series impedance $Z_{c}$ calculated using (1) is also plotted in Fig. 8. We can see that the impedance loop is moved to the inside of the circle SWR $=2$ (SWR $=$ standing wave ratio).

To demonstrate the accuracy of the impedance $Z_{c}$ obtained, we compare the input impedances $\left(Z_{\text {in }}\right)$ obtained through three different ways.

i) By a series impedance model [16]

$$
Z_{\text {in }}^{\text {series }}=Z_{c}-j Z_{0} \cot \beta l_{o}
$$

where $\beta$ is the propagation constant of the microstrip line and $l_{o}$ is the length $\left(l_{\mathrm{op}}\right)$ of the open stub plus the half length $(1.5 \mathrm{~mm})$ of the coupling stub, i.e., $l_{o}=l_{\mathrm{op}}+$ $1.5 \mathrm{~mm}$.

ii) By a two-port network [18]

where

$$
Z_{\text {in }}^{\text {two-port }}=Z_{0} \frac{1+\Gamma_{\text {in }}}{1-\Gamma_{\text {in }}}
$$

$$
\Gamma_{\text {in }}=S_{11}+\frac{S_{12} S_{21} \Gamma_{l}}{1-S_{22} \Gamma_{l}}
$$

with

$$
\Gamma_{l}=\frac{-j Z_{0} \cot \beta l_{o}-Z_{0}}{-j Z_{0} \cot \beta l_{o}+Z_{0}}
$$

iii) By a direct numerical simulation: $Z_{\text {in }}^{\text {direct }}$.

Fig. 9 displays the comparison of $Z_{\text {in }}^{\text {sines }}, Z_{\text {in }}^{\text {two-port }}$, and $Z_{\text {in }}^{\text {two-port }}$, showing no significant difference. This implies that the coupling between the microstrip feeding line and the

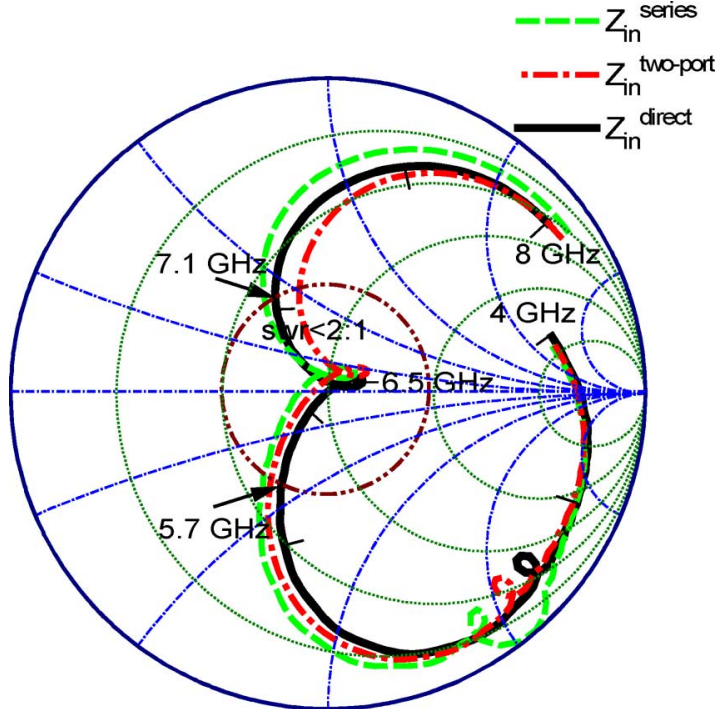

Fig. 9. Input impedance $Z_{\text {in }}$ of the cavity-backed slot/strip loop antenna when fed by a microstrip line $\left(Z_{\text {in }}^{\text {series }}\right.$ : calculated using a series impedance model; $Z_{\text {in }}^{\text {two-port }}$ : calculated using a two-port network; $Z_{\text {in }}^{\text {direct }}$ : obtained by direct simulation).

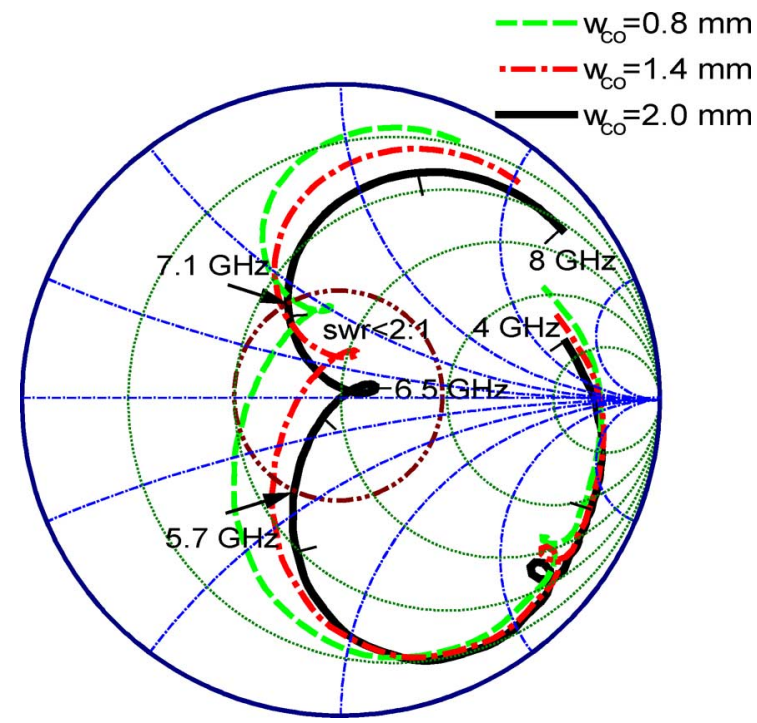

Fig. 10. Effect of the width ( $\left.w_{\mathrm{co}}\right)$ of the coupling stub on the input impedance $Z_{\text {in }}$ of the cavity-backed slot/strip loop antenna.

slot/strip loop can be modeled by a simple series impedance. Comparing the $Z_{\text {in }}$ in Fig. 9 to $Z_{c}$ in Fig. 8, we can also see that $Z_{\text {in }}$ and $Z_{c}$ have no obvious difference, which means that the open stub of the feeding line actually acts as a short circuit. Therefore only the length $\left(l_{\mathrm{op}}, l_{\mathrm{op}}+1.5 \mathrm{~mm}\right.$ is approximately a quarter guided wavelength) of the open stub is critical for the impedance matching, which was optimized to be $l_{\mathrm{op}}=6.5 \mathrm{~mm}$. A good impedance matching can be obtained by adjusting the coupling between feeding line and the slot/strip loop, i.e., the width $\left(w_{\mathrm{co}}\right)$ of the coupling stub. Fig. 10 demonstrates the effect of the width $w_{\mathrm{co}}$ on the input impedance of the microstrip-fed slot/strip loop antenna. The optimized value for $w_{\mathrm{co}}$ was found to be $w_{\mathrm{co}}=w=2 \mathrm{~mm}$. The dimensions of the cavity and the ground plane have no significant effect on the impedance matching. 


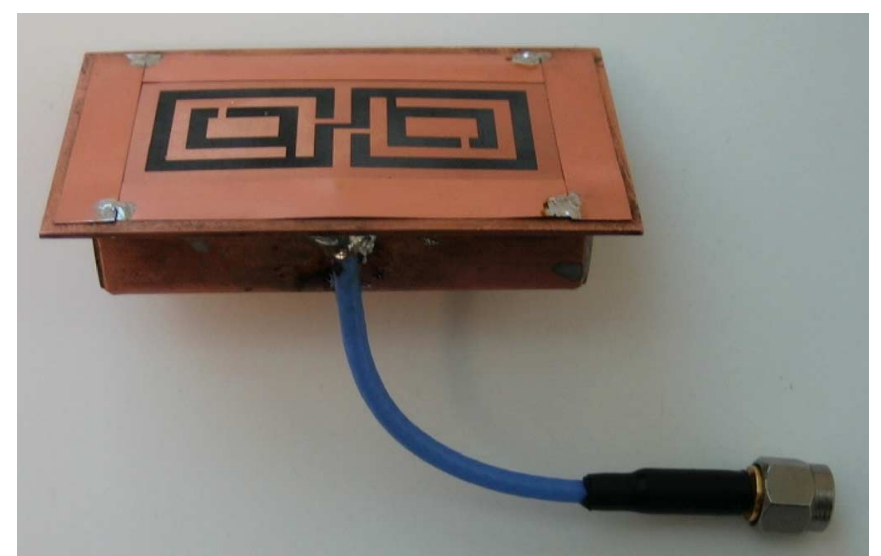

Fig. 11. Prototype of the cavity-backed slot/strip loop antenna.

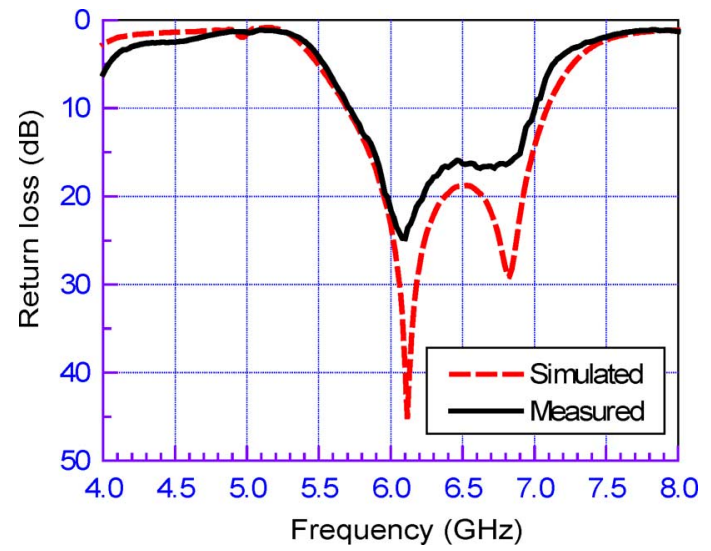

Fig. 12. Return loss of the cavity-backed slot/strip loop antenna.

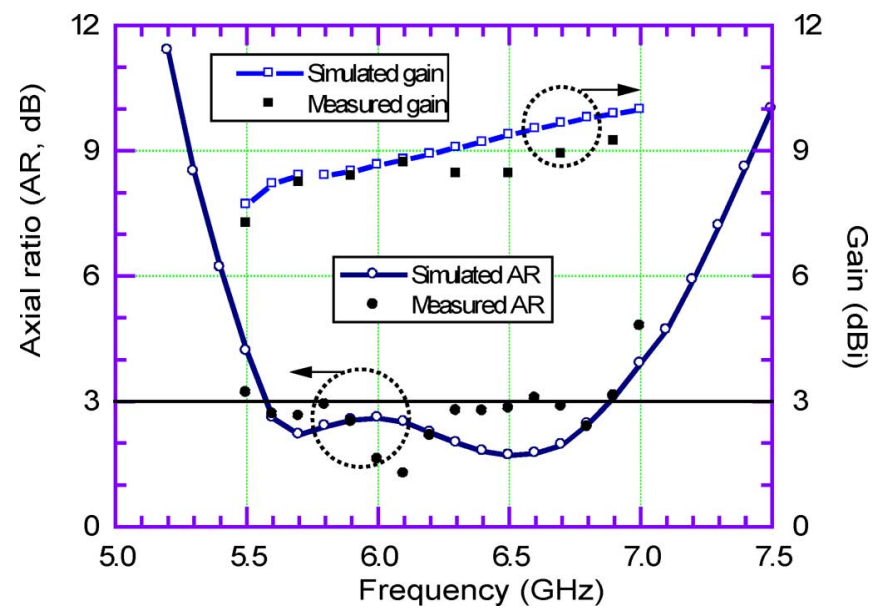

Fig. 13. Axial ratio and gain of the cavity-backed slot/strip loop antenna

\section{EXPERIMENTAL RESULTS}

A prototype of the cavity-backed slot/strip loop antenna is pictured in Fig. 11. A flexible coaxial cable is connected to the microstrip feeding line for measurement. Fig. 12 compares the measured return loss (RL) to the simulated result. A slight difference is probably due to the transition between the microstrip line and the coaxial cable. The measured bandwidth for $\mathrm{RL} \geq 10 \mathrm{~dB}$ is about $20 \%$. Fig. 13 shows the comparison of the simulated AR with the measured result. The measured bandwidth for $\mathrm{AR} \leq 3 \mathrm{~dB}$ is approximately $22 \%$, but there is a slight
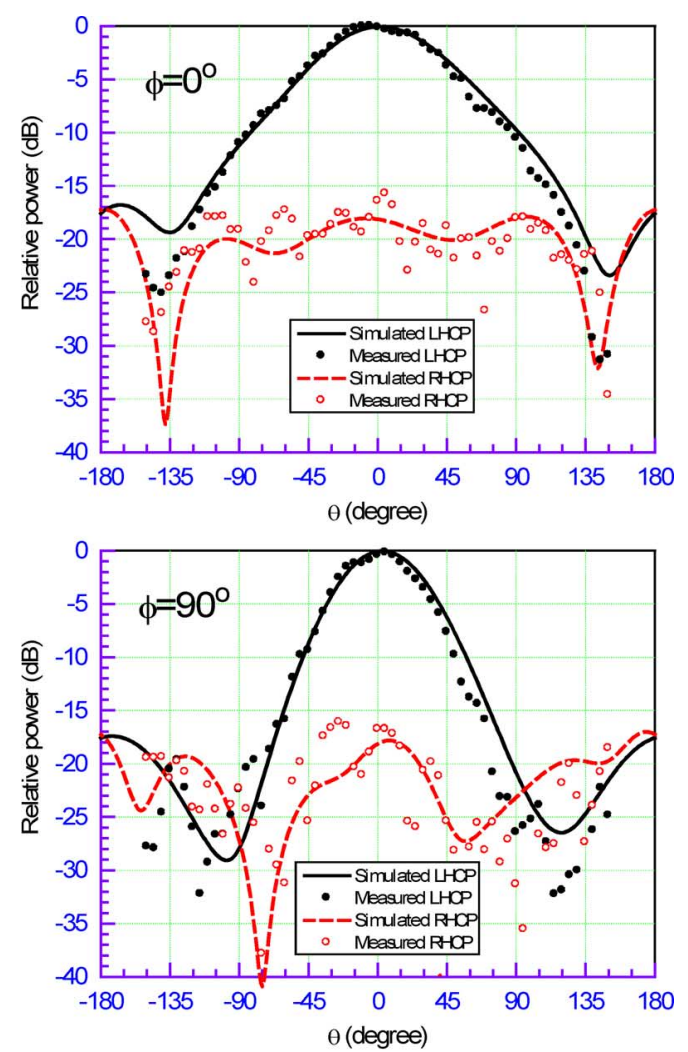

(a) $f=5.7 \mathrm{GHz}$.
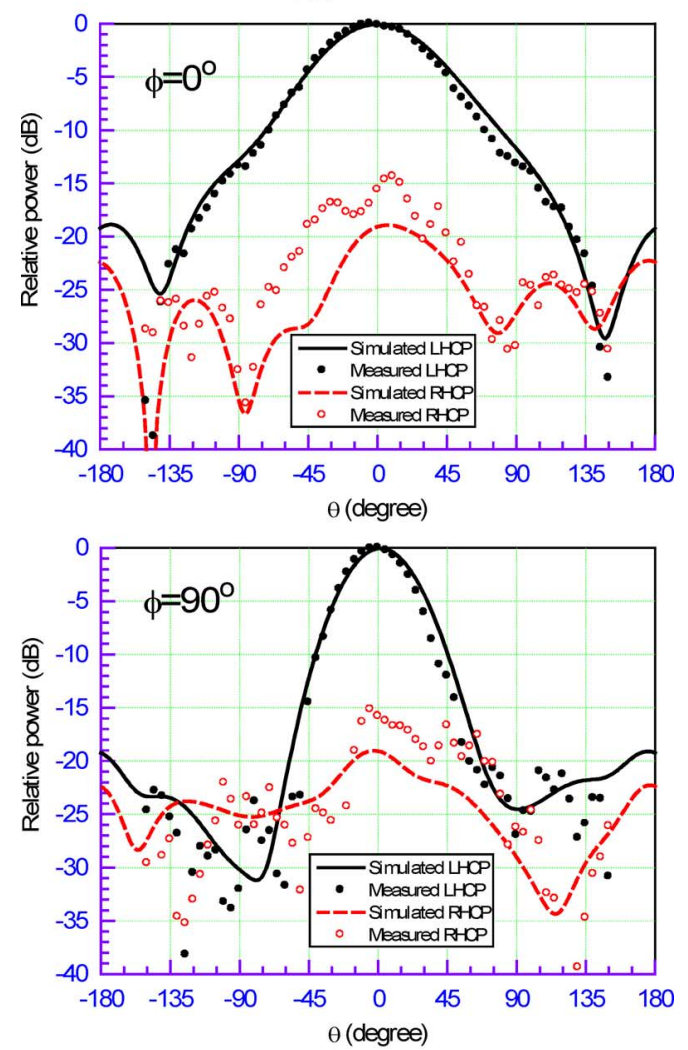

(b) $f=6.7 \mathrm{GHz}$.

Fig. 14. Radiation patterns of the cavity-backed slot-strip loop antenna.

bandwidth shift between the AR and RL. The overlapped bandwidth for $\mathrm{AR} \leq 3$ and $\mathrm{RL} \geq 10 \mathrm{~dB}$ is about $19 \%$. The gain of the cavity-backed slot/strip loop antenna is found to be around 
$9 \mathrm{dBi}$. The radiation patterns measured at $5.7 \mathrm{GHz}$ and $6.7 \mathrm{GH}$ are compared with the simulated results in Fig. 14 and good agreement is observed for the co-polarization (i.e., the left-hand circular polarization, LHCP) over the main beam. As expected, the beamwidth in the $\phi=0^{\circ}$ plane is wider than that in the $\phi=90^{\circ}$ plane because the length (i.e., $W_{s}$ ) of the antenna aperture in the $x$ direction is shorter than that (i.e., $L_{s}$ ) in the y direction. The cross-polarization [i.e., the right-hand circular polarization (RHCP)] is less than $-15 \mathrm{~dB}$. The discrepancies between the simulated and measured results for the axial ratio, gain, and radiation patterns are mainly due to the measurement errors. We used the NSI near-field antenna measurement system. Even though the antenna under test was setup at the far-field zone, the mechanical supporting structures of the system would still cause diffraction, introducing the measurement errors, particularly on the cross-polarized component. But the measurement has indeed demonstrated the broadband $\mathrm{CP}$ performance for the proposed antenna.

\section{CONCLUSION}

A cavity-backed slot/strip loop antenna has been developed for broadband CP operation. The slot/strip loop is a combination of a slot loop and a strip loop. The slot loop radiates a $\mathrm{CP}$ wave at a lower frequency while the strip loop produces $\mathrm{CP}$ radiation at a higher frequency. A combination of the two frequencies leads to a significant bandwidth enhancement. A simple microstrip line is introduced to feed the slot/strip loop antenna. It has been demonstrated that the proposed cavity-backed loop antenna can achieve a bandwidth of $19 \%$ for $\mathrm{AR} \leq 3 \mathrm{~dB}$ with $\mathrm{RL} \geq 10 \mathrm{~dB}$. The operating principles of the slot/strip loop antenna are investigated. Simulation and experimental results show good agreement.

\section{REFERENCES}

[1] A. Kumar and H. D. Hristov, Microwave Cavity Antennas. Norwood, MA: Artech House, 1989, pp. 101-213.

[2] K. Fujimoto and J. R. James, Eds., Mobile Antenna Systems Handbook2nd ed. Norwood, MA, Artech House, 2000, pp. 461-631.

[3] H. Morishita, K. Hirasawa, and K. Fujimoto, "Analysis of a cavitybacked annular slot antenna with one point shorted," IEEE Trans. Antennas Propag., vol. 39, no. 10, pp. 1472-1478, Oct. 1991.

[4] H. Hirose and H. Nakano, "Dual-spiral slot antennas," Proc. Inst. Elect. Eng. Microw. Antennas Propag., vol. 134, no. 1, pp. 32-36, Jun. 1991.

[5] S. Shi, K. Hirasawa, and Z. C. Chen, "Circularly polarized rectangularly bent slot antennas backed by a rectangular cavity," IEEE Trans. Antennas Propag., vol. 49, no. 11, pp. 1517-1524, Nov. 2001.

[6] T. Watanabe, K. Hirasawa, and S. Nemoto, "A rectangular-cavitybacked cloverleaf slot antenna for circular polarization," in Proc. 9th Int. Conf. Communications Systems, Sep. 2004, pp. 595-597.

[7] H. Nakano, K. Nogami, S. Arai, H. Mimaki, and J. Yamauchi, "A spiral antenna backed by a conducting plane reflector," IEEE Trans. Antennas Propag., vol. 34, no. 6, pp. 791-796, 1986.

[8] T. Ozdemir, J. L. Volakis, and M. W. Nurnberger, "Analysis of thin multioctave cavity-backed slot spiral antennas," Proc. Inst. Elect. Eng. Microw. Antennas Propag., vol. 146, no. 6, pp. 447-454, Dec. 1999.

[9] J. L. Volakis, M. W. Nurnberger, and D. S. Filipovic, "A broadband cavity slot spiral antenna," IEEE Antennas Propag. Mag., vol. 43, no. 6, pp. 15-26, Dec. 2001.

[10] Q. Li and Z. Shen, "An inverted microstrip-fed cavity-backed slot antenna for circular polarization," IEEE Antennas Wireless Propag. Lett., vol. 1, pp. 190-192, 2002.

[11] Micro-Stripes 7.0 Flomerics Group PLC, 2005.

[12] H. Morishita, K. Hirasawa, and T. Nagao, "Circularly polarized wire antenna with a dual rhombic loop," Proc. Inst. Elect. Eng. Microw. Antennas Propag., vol. 145, no. 3, pp. 219-224, Jun. 1998.
[13] R. L. Li and V. Fusco, "Printed figure-of-eight wire antenna for circular polarization," IEEE Trans. Antennas Propag., vol. 50, pp. 1487-1490, Oct. 2002.

[14] R. L. Li, G. GeJean, J. Laskar, and M. M. Tentzeris, "Investigation of circularly polarized loop antennas with a parasitic element for bandwidth enhancement," IEEE Trans. Antennas Propag., vol. 53, no. 12, pp. 3930-3939, Dec. 2005.

[15] R. L. Li, S. Basat, J. Laskar, and M. M. Tentzeris, "Development of wideband circularly polarised square- and rectangular-loop antennas with," Proc. Inst. Elect. Eng. Microw. Antennas Propag., vol. 153, no. 3, pp. 293-300, Jun. 2006.

[16] D. M. Pozar, "A reciprocity method of analysis for printed slot and slot-coupled microstrip antennas," IEEE Trans. Antennas Propag., vol. 34, no. 12, pp. 1439-1446, Dec. 1986.

[17] H. G. Akhavan and D. Mirshekar-Syahkal, "Approximate model for microstrip fed slot antennas," Electron. Lett., vol. 30, no. 23, pp. 1902-1903, Nov. 1994

[18] D. M. Pozar, Microwave Engineering, 2nd ed. New York: Wiley, 1998, pp. 211-216.

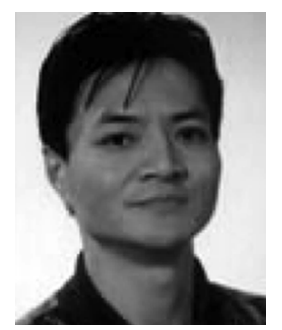

RongLin Li (M'02-SM'03) received the B.S. degree in electrical engineering from Xi' an Jiaotong University, China, in 1983 and the M.S. and Ph.D. degrees in electrical engineering from Chongqing University, China, in 1990 and 1994, respectively.

From 1983 to 1987, he worked as an Electrical Engineer at the Yunnan Electric Power Research Institute. From 1994 to 1996, he was a Postdoctoral Research Fellow at Zhejiang University, China, where, in 1998, he became a Professor. In 1997, he was with Hosei University, Japan, as an HIF (Hosei International Fund) Research Fellow. In 1999, he served as a Research Associate at the University of Utah, Salt Lake City. In 2000, he was a Research Fellow at Queen's University of Belfast, Belfast, U.K. Since 2001, he has been a Research Scientist II with the ATHENA Group at the Georgia Institute of Technology, Atlanta. His latest research interests include computational electromagnetics, modeling of antennas and microwave devices, and RF packaging design.

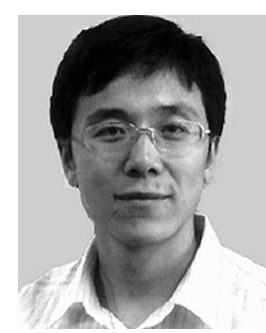

Bo Pan (S'03) received the B.S. and M.S. degrees (both with honors) from Tsinghua University, Beijing, China, in 2000 and 2003, respectively, and is currently working toward the $\mathrm{Ph} . \mathrm{D}$. degree at the School of Electrical and Computer Engineering, Georgia Institute of Technology, Atlanta.

Prior to beginning his Ph.D. studies, he worked as a Visiting Student at Microsoft Research Asia. $\mathrm{He}$ is currently a Graduate Research Assistant with the ATHENA Research Group and MiRCTECH Research Group at the Georgia Institute of Technology. $\mathrm{He}$ is also a research member of the Georgia Electronic Design Center (GEDC) and GT-NSF Packaging Research Center (PRC). His research involves the design and fabrication of antennas for multiple wireless applications design, as well as development and characterization of various components and circuits for RF/microwave/millimeter-wave T/R modules, with the focus on micromachining technologies. He has authored and coauthored over more than 20 papers in refereed journals and conference proceedings.

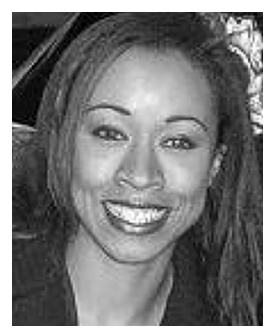

Anya N. Traille was born on January 31, 1982, in Washington, DC. She received the B.S. degree in electrical and computer engineering from the Georgia Institute of Technology (Georgia Tech), Atlanta, in 2004, where she is currently working toward the M.S. degree.

She is currently a member of the research faculty in the Sensors and Electromagnetic Applications Laboratory, Electronics and Antennas Division, Georgia Tech Research Institute (GTRI), working on radar system aperture design and analysis. She teaches various undergraduate classes and short courses including the Basic Antennas Concept course offered by GTRI to engineers across the U.S. Her current research includes conformal array synthesis, 3D data visualization, RFID readers, and nanotechnology. 


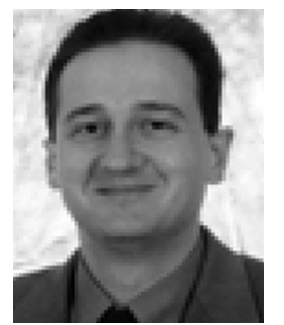

John Papapolymerou (S'90-M'99-SM'04) received the B.S.E.E. degree from the National Technical University of Athens, Athens, Greece, in 1993, and the M.S.E.E. and Ph.D. degrees from the University of Michigan, Ann Arbor, in 1994 and 1999, respectively.

From 1999 to 2001, he was an Assistant Professor in the Department of Electrical and Computer Engineering, University of Arizona, Tucson, and during summers 2000 and 2003 he was a Visiting Professor at the University of Limoges, France. From 2001 to 2005, he was an Assistant Professor at the School of Electrical and Computer Engineering, Georgia Institute of Technology (Georgia Tech), Atlanta, where he is currently an Associate Professor. His research interests include the implementation of micromachining techniques and MEMS devices in microwave, millimeter-wave and $\mathrm{THz}$ circuits and the development of both passive and active planar circuits on semiconductor ( $\mathrm{Si} / \mathrm{SiGe}, \mathrm{GaAs})$ and organic substrates (LCP, LTCC) for system-on-a-chip (SOC)/ system-on-a-package (SOP) RF front ends. $\mathrm{He}$ has authored or coauthored over 140 publications in peer reviewed journals and conferences.

Dr. Papapolymerou received the 2004 Army Research Office (ARO) Young Investigator Award, the 2002 National Science Foundation (NSF) CAREER award, the Best Paper Award at the 3rd IEEE Int. Conf. Microwave and Millimeter-Wave Technology (ICMMT2002), Beijing, China, and the 1997 Outstanding Graduate Student Instructional Assistant Award presented by the American Society for Engineering Education (ASEE), University of Michigan Chapter. His student also received the Best Student Paper Award at the 2004 IEEE Topical Meeting on Silicon Monolithic Integrated Circuits in RF Systems, Atlanta, GA. He currently serves as the Vice-Chair for Commission D of the U.S. National Committee of the URSI and as an Associate Editor for the IEEE Microwave and Wireless COMPONENT LetTERS and the IEEE TRANSACtions on ANTENNAS AND PROPAGation. During 2004 he was the Chair of the IEEE MTT/AP Atlanta Chapter.

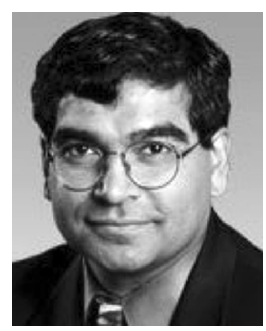

Joy Laskar (S'84-M'85-SM'02-F'05) received the B.S. degree in computer engineering (highest honors) from Clemson University, Clemson, SC, in 1985, and the M.S. and the Ph.D. degrees in electrical engineering from the University of Illinois at Urbana-Champaign, in 1989 and 1991, respectively.

Prior to joining the Georgia Institute of Technology (Georgia Tech), Atlanta, in 1995, he held faculty positions at the University of Illinois and the University of Hawaii. At Georgia Tech he holds the Schlumberger Chair in Microelectronics in the School of Electrical and Computer Engineering. He is also the Founder and Director of the Georgia Electronic Design Center and heads a research group of 250 members (graduate students, research staff, and administration) with a focus on integration of high-frequency mixed-signal electronics for next-generation wireless and wire line systems. Between 1995 through summer 2007, he graduated $31 \mathrm{Ph} . \mathrm{D}$. students. He has authored or coauthored more than 400 papers, several book chapters, three books (with two books in development), numerous invited talks and has more than 40 patents issued or pending. His work has resulted in the formation of two companies. In 1998 he co-founded an advanced WLAN IC Company: RF Solutions, which is now part of Anadgics (Nasdaq: Anad). In 2001, he co-founded a next generation analog CMOS IC company, Quellan, which is developing collaborative signal-processing solutions for the enterprise, video, storage and wireless markets.

Dr. Laskar's honors include the Army Research Office's Young Investigator Award in 1995, the National Science Foundation's CAREER Award in 1996, NSF Packaging Research Center Faculty of the Year in 1997, and co-recipient of the IEEE Rappaport Award (Best IEEE Electron Devices Society Journal
Paper) in 1999. He was faculty advisor for the 2000 IEEE MTT IMS Best Student Paper award, was Georgia Tech Faculty Graduate Student Mentor of the year in 2001, received a 2002 IBM Faculty Award, and the 2003 Clemson University College of Engineering Outstanding Young Alumni Award. He was the 2003 recipient of the Outstanding Young Engineer award of the Microwave Theory and Techniques Society and was named an IEEE Fellow in 2005. For the 2004-2006 term, he served as an IEEE Distinguished Microwave Lecturer and currently is an IEEE EDS Distinguished Lecturer. He received Georgia Tech's "Outstanding Faculty Research Author" award in 2007, and has been appointed General Chairman of the IEEE International Microwave Symposium 2008.

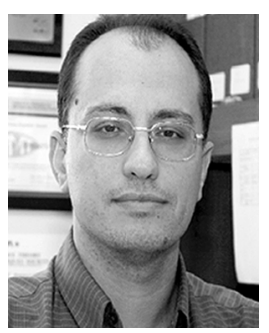

Manos M. Tentzeris (S'89-M'98-SM'03) received the Diploma Degree in Electrical and Computer Engineering (magna cum laude) from the National Technical University of Athens, Athens, Greece and the M.S. and Ph.D. degrees in electrical engineering and computer science from the University of Michigan, Ann Arbor.

$\mathrm{He}$ is currently an Associate Professor with School of School of Electrical and Computer Engineering, Georgia Institute of Technology (Georgia Tech), Atlanta. He has published more than 260 papers in refereed journals and conference proceedings, two books, and ten book chapters. He has helped develop academic programs in highly integrated/ multilayer packaging for RF and wireless applications using ceramic and organic flexible materials, paper-based RFID's and sensors, microwave MEM's, SOP-integrated (UWB, mutliband, conformal) antennas and adaptive numerical electromagnetics (FDTD, multiresolution algorithms) and heads the ATHENA Research Group, Georgia Tech, (20 researchers). He is the Georgia Electronic Design Center Associate Director for RFID/sensors research, and he has been the Georgia Tech NSF-Packaging Research Center Associate Director for RF Research and the RF Alliance Leader from 2003-2006. He was a Visiting Professor with the Technical University of Munich, Germany for summer 2002, where he introduced a course in the area of high-frequency packaging. He has given more than 50 invited talks in the same area to various universities and companies in Europe, Asia, and America.

Dr. Tentzeris was the recipient/co-recipient of the 2007 IEEE APS Symposium Best Student Paper Award, the 2007 IEEE IMS Third Best Student Paper Award, the 2007 ISAP 2007 Poster Presentation Award, the 2006 IEEE MTT Outstanding Young Engineer Award, the 2006 Asian-Pacific Microwave Conference Award, the 2004 IEEE Transactions on Advanced Packaging Commendable Paper Award, the 2003 NASA Godfrey "Art" Anzic Collaborative Distinguished Publication Award, the 2003 IBC International Educator of the Year Award, the 2003 IEEE CPMT Outstanding Young Engineer Award, the 2002 Int. Conf. Microwave and Millimeter-Wave Technology Best Paper Award (Beijing, China), the 2002 Georgia Tech-ECE Outstanding Junior Faculty Award, the 2001 ACES Conference Best Paper Award and the 2000 NSF CAREER Award, and the 1997 Best Paper Award of the International Hybrid Microelectronics and Packaging Society. He was also the 1999 Technical Program Co-Chair of the 54th ARFTG Conference, Atlanta, and the Chair of the 2005 IEEE CEM-TD Workshop. He is the Vice-Chair of the RF Technical Committee (TC16) of the IEEE CPMT Society. He has organized various sessions and workshops on RF/Wireless Packaging and Integration, RFID's, Numerical Techniques/Wavelets, in IEEE ECTC, IMS, VTC and APS Symposia in all of which he is a member of the Technical Program Committee in the area of "Components and RF." He will be the TPC Chair for IEEE IMS 2008 Symposium. He is an Associate Editor of the IEEE TRANSACTIONS ON ADVANCED PACKAGING. He is a member of URSI Commission D, the MTT-15 Committee, an Associate Member of EuMA, a Fellow of the Electromagnetic Academy, and a member of the Technical Chamber of Greece. 